\title{
PESQUISAS EM CADEIA
}

\section{RESUMO}

ESTE ENSAIO É UM RELATO DE EXPERIÊNCIAS DE PESQUISAS EM CADEIA. CADEIA É METONÍMIA PARA O ARQUIPÉLAGO PUNITIVO - MANICÔMIOS JUDICIÁRIOS, PRISÕES E UNIDADES SOCIOEDUCATIVAS. AO FINAL, PROVOCO AS FORMAS DE ESCRITURA E VIDÊNCIA SOBRE CADEIAS E BANDIDOS. ARRISCO DIZER QUE AS PESQUISAS SOBRE CADEIA SÃO MASCULINAS NA ESCRITA E NA VIDÊNCIA.

\section{PALAVRAS-CHAVE}

CADEIA; PRISÃO; MANICÔMIO JUDICIÁRIO; UNIDADE SOCIOEDUCATIVA; PESQUisa EMPÍRICA EM DIREITO.

\section{Pesquisas em CAdeia ${ }^{1}$}

Este ensaio é uma memória pessoal das pesquisas em cadeia que desenvolvi na última década no Brasil: foram estudos em manicômios judiciários, presídios e unidades socioeducativas. Entre espaços institucionais, métodos e resultados de pesquisa, compartilho minhas inquietações como pesquisadora. Comecei a

\author{
ABSTRACT \\ THIS PAPER IS A PERSONAL ACCOUNT OF MY RESEARCH \\ EXPERIENCES IN BRAZILIAN PRISONS. PRISON IS A FIGURE \\ OF SPEECH, WHICH REPRESENTS A PUNITIVE ARCHIPELAGO \\ - FORENSIC HOSPITALS, JAILS, AND YOUTH DETENTION \\ CENTERS. AT THE END, I PROVOKE A DEBATE OVER FORMS \\ OF SEEING PRISONS AND PERSONS AND WRITING ABOUT \\ THEM. I DARE SAY THE STUDIES ABOUT PRISON ARE MALE \\ GENDERED BASED.

\section{KEYWORDS} \\ JAIL; PRISON; FORENSIC HOSPITAL; YOUTH \\ DETENTION CENTER; LAW EMPIRICAL RESEARCH.
}

pesquisa em cadeia com um filme, o revés do que aconselharia qualquer livro de metodologia (A casa dos mortos, 2008). Um filme é o fim de uma pesquisa, pois o roteiro pede conhecimento denso e íntimo. Nada disso eu tinha, só o olhar frouxo de quem desconhece tudo. Ainda assim, me permiti viajar e visitar 
os manicômios judiciários do país e, na busca de um roteiro, camadas de dificuldade amplificadas pelos regimes de segredo, proteção e proibição martelavam meu juízo. Fiz o primeiro circuito nacional: encontrei calabouços, gente nua, grade aberta, comida pelo chão; multidão e esquecidos em presídios. Ouvi histórias e cantorias, anotei relatos de campo com os olhos mais abertos que as orelhas: o escondido seria contado por imagens. A passagem do vivido à narrativa pedia sensibilidade sobre a audiência, uma prática que deve acompanhar qualquer pesquisadora de cadeia.

\section{a Casa dos Mortos}

Cheguei ao único manicômio judiciário de Salvador, com uma população de 158 habitantes, em 2008. Antes de mim, promotores de justiça haviam decretado um termo de ajustamento de conduta - o documento liberou metade do povo e processou a equipe de saúde. O diretor me acolheu com o alento de quem via a arte chegar depois do furacão da polícia: nada de pior poderia ser contado sobre aquele lugar se comparado ao denunciado pelas manchetes de jornais. Não me travesti de psiquiatra, fiz questão de me apresentar como contadora de histórias, o jaleco branco era só para arrumar roupa conhecida enquanto caminhava sem agentes de segurança. Esse foi o acordo: sozinha por onde quisesse, mas com jaleco. Em uma das cenas do filme, exibo o escondido de método - ali estou, com o jaleco branco, entre grupo em cantoria (DINIZ, 2013a).

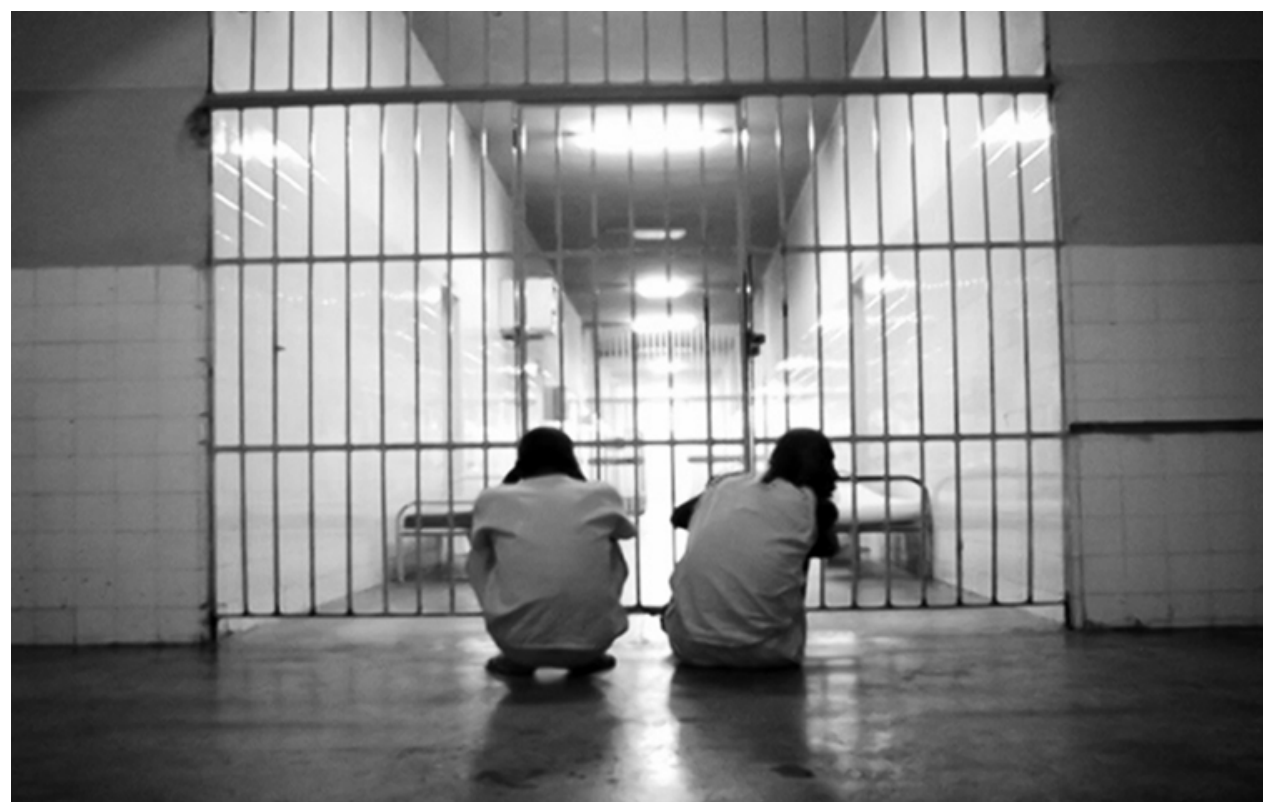

CASA DOS MORTOS. DEBORA DINIZ, 2008. 
Assumi alguns cuidados éticos como reguladores do filme: não exibiria falta de roupa ou situações humilhantes; os personagens teriam que consentir antes, durante e ao final da montagem do filme; não haveria remuneração pela participação; a narrativa seria documental; a equipe de filmagem seria só eu e os assistentes de câmera e de som (DINIZ, 2014). Além dessas regras próprias, respondi a diversas camadas criativas de burocracia para entrada nos manicômios: comitês de ética e autorizações diretoras, familiares ou médicas. Desacredito de filmes sobre o povo de cadeia sem exibir rostos e biografias, vozes e jeitos: a estética do encobrimento é também a do medo - pode até ser que se justifique pelo risco de estigma, mas não aproxima a audiência de quem é descrito como perigoso, louco ou bandido.

Iniciei a pesquisa no manicômio judiciário de Salvador com a figura do ladrão de bicicleta, personagem encontrado em todos os hospitais-presídios que visitei. Com Almerindo, a profecia se realizava. Mas o filme não poderia ser apenas sobre o bom selvagem, seria muita tranquilidade para uma audiência certa de que ali estão os loucos bandidos em surto. Passei meses vasculhando os arquivos do hospital, e assim conheci os 158 habitantes - primeiro, pelos dossiês (esse monturo de papéis produzido pela engrenagem policial, penal e tutelar), para depois me apresentar a eles. Fui de ala em ala, conversei com as lideranças, negociei presença: o termo de consentimento para a pesquisa e o de cessão de imagens para o filme foi acordado com cada habitante e com o diretor do hospital, e uns poucos recusaram participação; desses, o filme não mostra rosto, e os dossiês foram esquecidos. Passei a perambular pelo hospital; sozinha e sem câmera, respondia curiosidades, apresentava-me a cada dia vestindo o jaleco branco e anunciando a chegada da câmera, que apareceu em dia festivo: uma competição de futebol entre hospícios da cidade. Essa é a abertura do filme; genuinamente, o primeiro instante de aproximação da câmera. Os meses seguintes foram de gravações, totalizando mais de 50 horas de filmagens. Com o filme pronto, voltei ao manicômio judiciário; os habitantes foram os primeiros a assistir e concordar com a história contada.

Do filme, voltei para a ciência dos números. As visitas me mostraram que sabíamos pouco sobre quem e quantos eram aqueles habitantes, desde quando e por que estavam nos manicômios judiciários. Coordenei o censo da população de hospitais de custódia e tratamento psiquiátrico (HCTPs) e alas de tratamento psiquiátrico em presídios (ATPs), pois sequer se conhecia o número de instituições no país (DINIZ, 2013b). Em 12 meses, visitamos 26 instituições, abrimos os documentos de cada indivíduo internado: a pesquisa foi feita nos dossiês produzidos pelas unidades como arquivos da loucura bandida (FARGE, 2009). O instrumento de coleta foi digital; a equipe de campo era de jovens pesquisadoras de pós-graduação e perseguia perguntas claras: há causalidade entre diagnóstico psiquiátrico e crime? Qual é o perfil da população? Há quanto 
tempo vivem em clausura? Como a engrenagem de direitos se movimenta? Essas perguntas se transformavam em questões do instrumento e respondiam a hipóteses de pesquisa. Encontramos 3.989 indivíduos, sendo 1.033 provisórios e 2.956 em medida de segurança; 3.684 eram homens, e 291 mulheres: quase todos pretos ou pardos, com pouca escola, nenhum trabalho, sozinhos ou solteiros (DINIZ, 2013b). O escandaloso é que pelo menos um em cada quatro indivíduos não deveria estar mais por ali (por laudo vencido, cessação de periculosidade, sem sentença ou com extinção da medida de segurança); para 55 deles, o Estado não sabe por que mantê-los em tratamento compulsório, pois têm medida de segurança extinta. E a surpresa que agonia: 18 deles estavam presos havia mais de 30 anos. Entre o grupo dos esquecidos, estava Zefinha, que vive há 38 anos em Alagoas.

\section{ZEFINHA}

Foi assim que voltamos ao manicômio judiciário de Alagoas para contar a história de Zefinha, a mulher há mais tempo abandonada no país: no grupo dos 18 esquecidos, Zefinha é a única mulher (DINIZ, 2015d; DINIZ; BRITO, 2016). Após novas autorizações, o corpus de pesquisa foi o dossiê do hospital; processo judicial e fotografias da sobrevivência em uma minúscula cela se juntaram para entender o passado e o presente de abandono. Se o filme tinha me dado experiência sobre como escavar vivências em um manicômio, a inquietação metodológica era nova: não seria mais arte de filme ou número sem nome, mas uma história de acontecimento único. Zefinha é só ela, não nomeá-la seria transformá-la em outra ou qualquer, como se uma nova camada de silenciamento lhe fosse imposta - primeiro, pelo dobramento ubuesco penal-tutelar (FOUCAULT, 2010); depois, por nós, as escritoras que escavaram uma lenda desaparecida (DINIZ, 2015d; DINIZ; BRITO, 2016). Zefinha não é um estudo de caso, daqueles com propriedades heurísticas para falar das 291 mulheres na multidão dos loucos bandidos. Velha, com esquizofrenia e acusada de lesão corporal, é só ela. E nenhuma outra com mais de década vivendo em manicômio judiciário. 


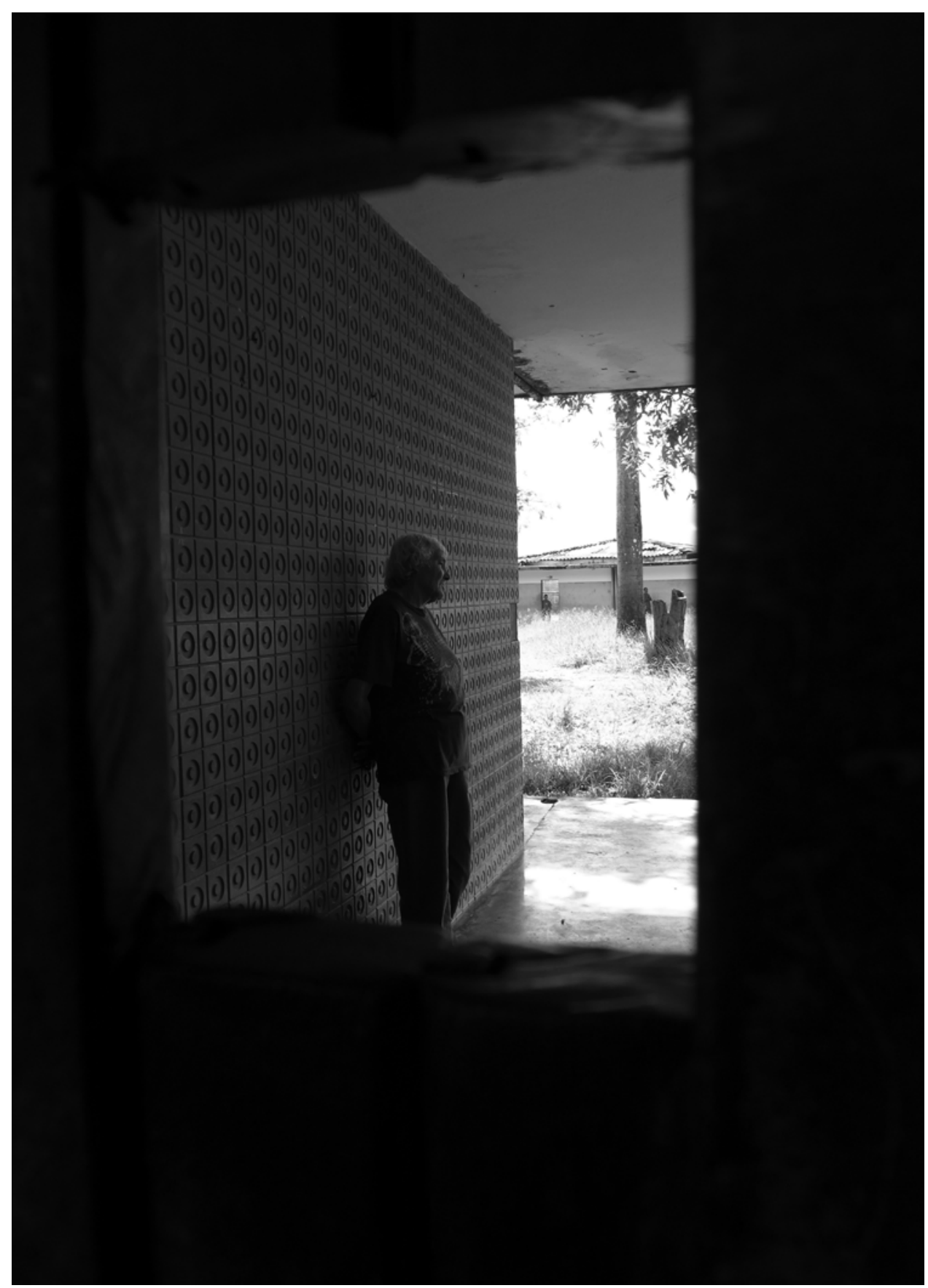

ELA, ZEFINHA. DEBORA DINIZ, 2014. 
Zefinha é pesquisa de acontecimento único, e por duas razões falo em acontecimento. ${ }^{2}$ A primeira é por ser Zefinha um acontecimento arqueológico - sua história nos mostra como se deu a metamorfose da louca bandida na velha abandonada, ou seja, desnuda as condições de possibilidade da existência do manicômio judiciário em uma época tutelar da loucura. Zefinha é ainda infame, aquela cuja existência imortalizou-se pelo cruzamento com o poder e da qual só sabemos fragmentos de notícias (FOUCAULT, 2012). Zefinha é ela só, sem parentes ou aderentes no fora; até recentemente, nem documentos tinha: a personagem obscura da vida dos homens infames. Uma desaparecida, indocumentada, sem luto pela ausência, cuja aproximação com a história nos provoca o ardor da infâmia, como disse Michel Foucault (2012).

A segunda razão é pelo escândalo da singularidade de Zefinha. Encontrá-la é repetir a pergunta de Primo Levi (1988) sobre os sobreviventes de campos de concentração (aqui não recorro a uma reductio ad Hitlerum): "É isto uma mulher?" Nomear Zefinha é reconhecê-la, aparecê-la para a cena da inteligibilidade dos direitos, mas como fazer isso se a mulher não mais relata a si mesma? (BUTLER, 2015): oferecendo o testemunho de um rosto e um passado, mas em uma história de nosso tempo "podemos, então perguntar-nos se vale mesmo a pena, se convém que de tal situação humana reste alguma memória. A essa pergunta, tenho a convicção de poder responder que sim. Estamos convencidos de que nenhuma experiência humana é vazia de conteúdo, de que todas merecem ser analisadas; de que se podem extrair valores fundamentais (ainda que nem sempre positivos) desse mundo particular que estamos escrevendo" (LEVI, 1988, p. 88). Como Levi, estou convencida que sim Zefinha grita os sem sentidos da cadeia, da apartação da loucura, e as consequências da vida fora do bando (AGAMBEN, 2007). Há novidade e regularidade na escavação do acontecimento arqueológico.

Como uma mulher infame, cuja história é obscura, os murmúrios sobre Zefinha a tornam uma personagem lendária; “o lendário, seja qual for seu núcleo de realidade, finalmente não é nada além do que a soma do que se diz. Ele é indiferente à existência ou inexistência daquele de quem ele transmite a glória” (FOUCAULT, 2012, p. 208). O que sabemos de Zefinha é o que dela foi arquivado pela escrita disciplinare, em quase 40 anos de internação, foram 90 páginas de dossiê e 108 páginas de processo judicial. É tudo que sabemos, pois a lenda "[...] é, por sua natureza, sem tradição; rupturas, apagamento, esquecimento, cancelamentos, reaparições, é apenas através disso que ela pode nos chegar" (FOUCAULT, 2003, p. 209). Por isso, Zefinha saiu dos números e foi apresentada com nome e lenda própria, com rosto e reclame de inteligibilidade aos direitos - é a mulher mais antiga supervivente às relações de poder e força sobre a loucura criminosa. 


\section{Cadeia de mulheres}

Cheguei à cadeia feminina da capital do país com os modos tradicionais de cientista social: prancheta, questionários, hipóteses e autorizações. O pedido era ousado, mover o presídio para que todas as mulheres em regime fechado de prisão fossem entrevistadas. Assim foi feito, os jeitos foram meio tortos, mas os disponíveis para retratar a massa: as mulheres saíam das celas, arrumavam-se em blocos de 10 ou 20 na capela e, sempre na presença de agentes de segurança, respondiam aos questionários. As perguntas eram definidas previamente por nós, não havia isso de escutar e rever o que poderia ser conhecido: queríamos ciência para o que se escondia nas dificuldades de pesquisa em presídio. O questionário não pedia privacidade, as perguntas eram anunciadas e respondidas, preenchidas pela pesquisadora, que segurava a prancheta e a caneta. É desse método de pesquisa que anunciamos: uma em cada quatro mulheres presas em regime fechado passou por unidades socioeducativas de internação na adolescência. Elas são jovens, pretas e pardas, de pouca escola e trabalho informal, com filhos no fora ou por ali (DINIZ; PAIVA, 2014). Estão presas pelo comércio ilegal de drogas ou, como contou uma delas, "por vender maconha com pamonha” (DINIZ, 2015a).

Pelos manuais de pesquisa, o feito recebe nome importante - censo das mulheres em regime fechado quanto a perfil, benefícios sociais, trabalhos e escolas. Sistematizamos o que já se sabia de outros estudos localizados ou, talvez, sem tão grande magnitude quanto a de um censo. O dado é poderoso, mas estranho jeito de fazer acadêmico pela distância da realidade da vida em prisão. Chegamos ali com os trejeitos típicos de pesquisadoras iluminadas, "Você é livre para participar”, anunciávamos. Não importa o que fôssemos fazer, sem vínculo com as mulheres, o anúncio da liberdade como possibilidade teria única resposta, "Não". Poder escolher em presídio é resistir às ordens, até porque elas são soberanas quando ditadas pelo colete preto da vigilância. Saímos à procura de outra forma de aproximar os sentidos da pesquisa o anúncio da liberdade de escolha era convite à recusa, e nossas aparências de mulheres distantes da realidade da cadeia eram território estrangeiro, ao que a epistemologia da "vista do ponto" melhor explicava que a do "ponto de vista" (HARAWAY, 1995). Como benefício compartilhado pela pesquisa, os questionários moviam agenda de demandas e necessidades; montamos plantão de socorro para as visitadoras ou presas. Ao final, só duas mulheres se recusaram a responder ao questionário.

Depois de muito perguntar, ouvir respostas a perguntas pré-determinadas, resolvi retornar à cadeia de outro jeito: sentei-me no Núcleo de Saúde do presídio durante seis meses, de onde só tomei notas do vivido e ouvido entre presas e jaleco branco (DINIZ, 2015a). Cadeia é espaço organizado pelas cores do poder: preto é cor de vigilância; branco, de visitadora de quinta-feira; laranja, de presa. Cheguei a pensar em uma quarta cor para acomodar-me no Núcleo de Saúde - diferente do manicômio judiciário, 
nem cogitei o branco como passe livre para escuta; queria gritar escuta diferente, por isso vesti preto, a cor da vigilância. Uma presa não me confundia com a carcereira, faltava-me não só a imponência do corpo, mas o brasão da segurança e a voz de mando. Do pouco que falei, foi só para me apresentar e arranhar pedido de consentimento, mas, com o tempo, até isso foi feito pelo jaleco branco em meu lugar.

No Núcleo de Saúde escutei necessidades e precisões, tomei nota do vivido no instante do dito e negociado, pois, como disse, nunca fiz pergunta a presa. Não me descrevo como invisível naquele apertado conjunto de salas, mas como desimportante. Os minutos de acolhimento pelo jaleco branco são preciosos para serem gastos com escutadeira que se anuncia como pesquisadora. Uma presa teve que atravessar barreiras de poder para ser ouvida pelo jaleco branco: um catatau - pequeno bilhete do tamanho de um telegrama, a escrita típica de presídio - sai da cela, é recolhido no pátio por colete preto, para ser selecionado por curadora do Núcleo de Saúde, antes de chegar à mesa de jaleco branco do atendimento. Foi do assento da escuta que ouvi as histórias no miúdo e na multidão: por ali passaram as loucas, as suicidas, as mães e as grávidas, as indígenas ou muito jovens, as crackeiras e as bicudas.

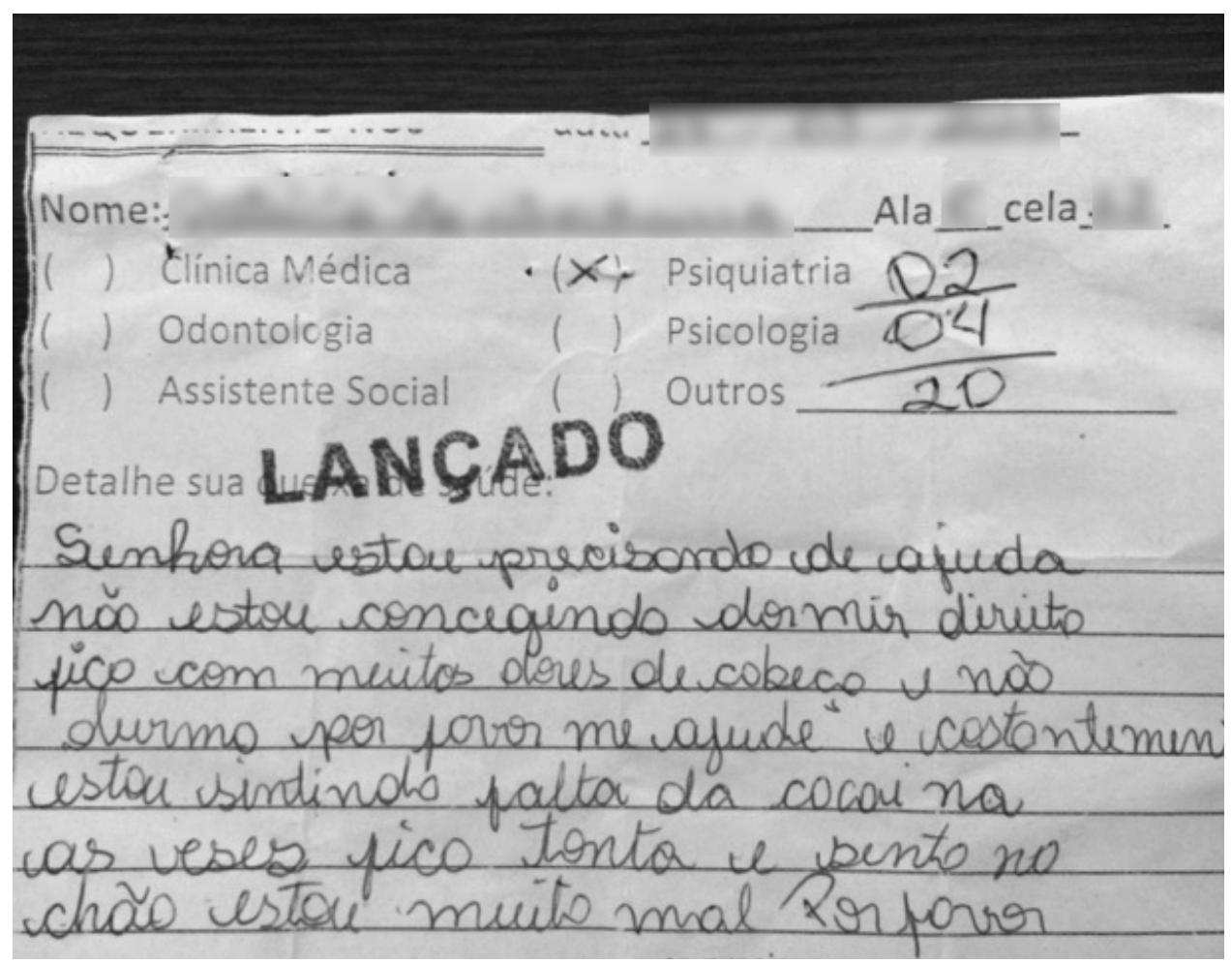




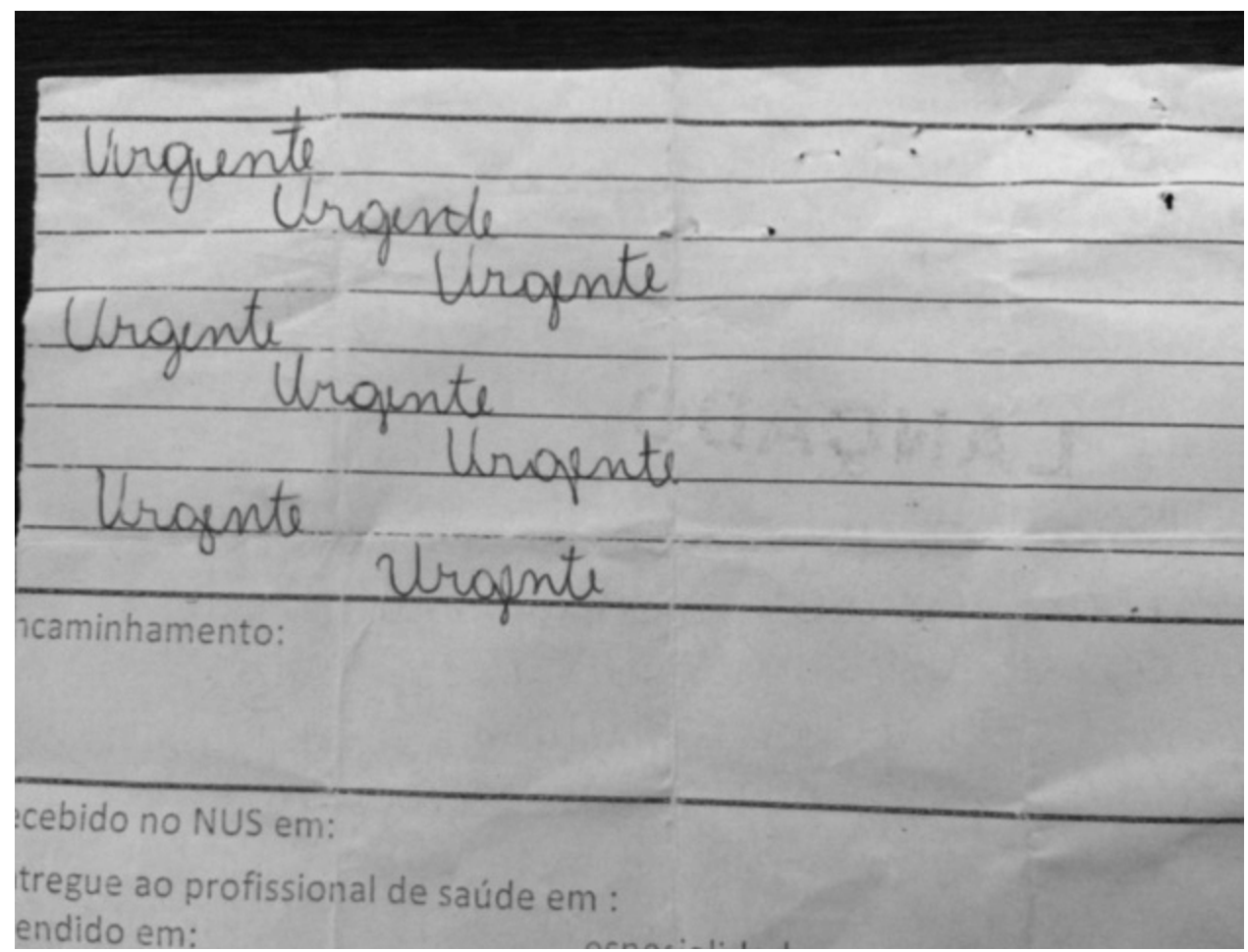

CATATAU. DEBORA DINIZ, 2013.

No livro Cadeia: relatos sobre mulheres, conto a história de 50 encontros (DINIZ, 2015a). Não pude voltar ao presídio para ler as narrativas, como fiz no filme $A$ casa dos mortos. ${ }^{3}$ Sem ter as presas como leitoras, resolvi fazer retorno noutro lugar: na cadeia de papel, o reformatório compulsório que acomodou uma em cada quatro mulheres para o futuro na prisão. Há quase um ano, frequento a unidade socioeducativa de internação da capital do país. Por ali, ouço histórias, observo a vida, durmo na jega, tiro fotos e troco cartas. Faço o que se apresenta nos manuais como etnografia, mas prefiro descrever o método por palavreado conhecido na casa: "puxo um plantão”.

\section{Cadeia de Papel}

Um plantão é de 24 horas a cada três dias: esse é meu ritmo na cadeia de papel. O nome não foi inventado por mim, mas é palavra conhecida como ironia própria pelas meninas que ali vivem nem tanto uma cadeia, mas já um projeto de prisão. Como puxadora de plantão, ainda não tinha aprendido tudo que devia na cadeia quando ali cheguei, ainda com os modos de manual de pesquisa, só sem prancheta ou gravador. 
Novamente vesti preto e, com voz de quem já tem geração de avó de quem ali habita, anunciei ser pesquisadora e escritora. Me ouviram admiradas como eu não seria uma pastora ou oficineira? O tema de deus ou da arte foi logo esquecido, mas as meninas reclamaram escritos que atestassem o título de escritora. Montei pasta variada de escritos estranhos - aborto ou racismo eram alguns dos temas - e a distribuí nas celas. As meninas queriam me conhecer antes que eu lhes fizesse perguntas: foi assim que falamos primeiro sobre quem eu era, o que penso e escrevo, para devagar minhas vontades de pesquisadora serem aceitas (DINIZ, 2015b). O encontro foi traduzido novamente por elas, "vamos pegar sentimento, d. Debora”.

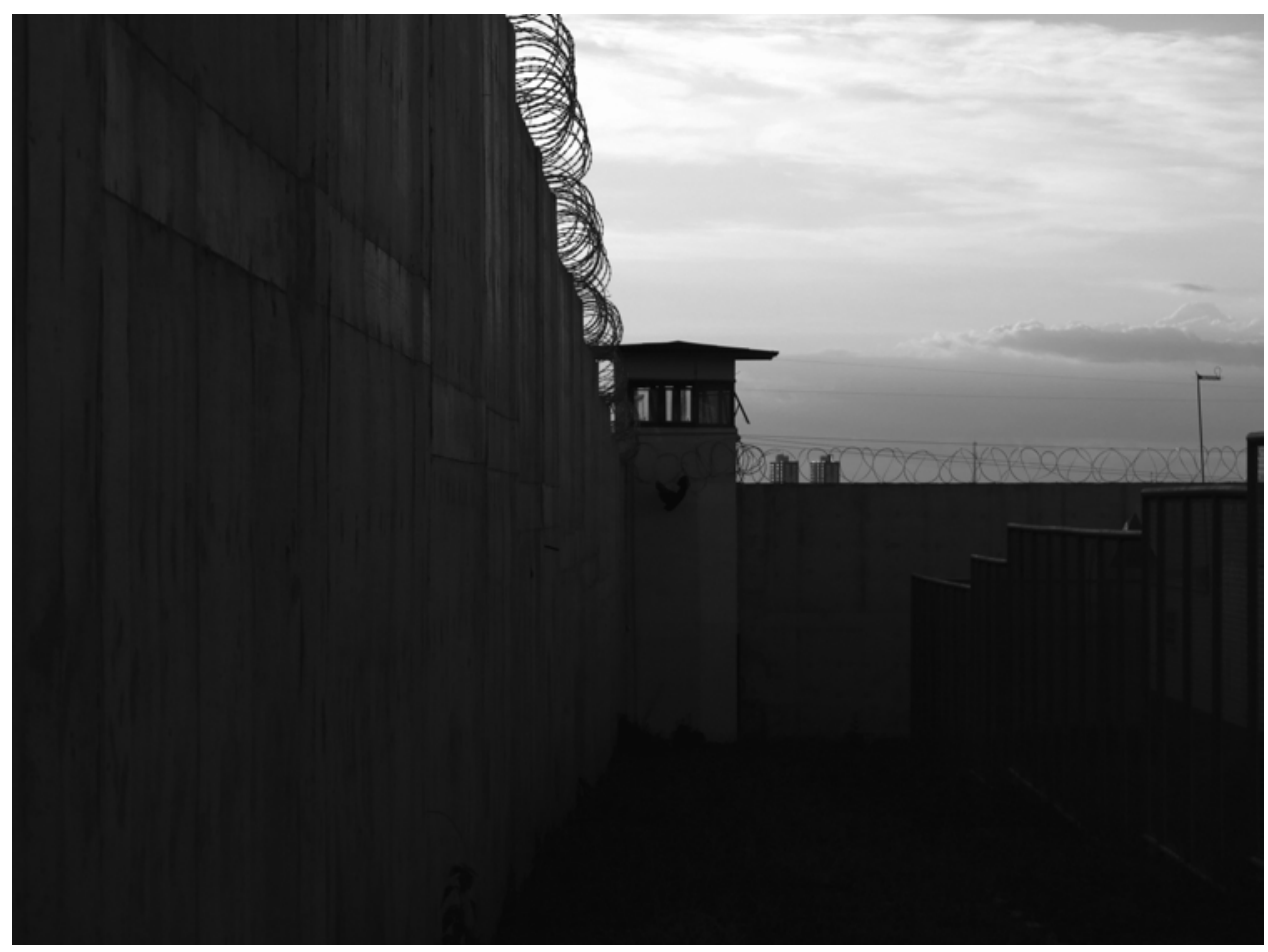

CADEIA DE PAPEL. DEBORA DINIZ, 2015.

Foi preciso o tempo de manicômio e de presídio feminino para entender o quanto a escrita é sobrevivência para a vida em cadeia (ARTIÉRES, 2014; GOMÉZ; BLAS, 2005). Na cadeia de papel, os escritos estão por todos os lados - na parede das celas das provisórias, nos bilhetes da escola, nas cartas que passamos a trocar. Como puxadora de plantão, sigo o ritmo da vida regrada 
pelos conferes e revistas, pela escola, pelo banho de sol, pelo corre da faxina, pelo recolher noturno, mas, principalmente, pela escrita e leitura de cartas. São já centenas delas: começamos pela literatura, deslizamos para o passado e pelos segredos, e o assunto não termina enquanto a sentença de liberdade não é decretada. As cartas são letras da solidão, mas integram uma ordem disciplinar da escrita como forma de arrependimento: cadeias são instituições cuja memória e permanência se dá pela escrita disciplinar e normalizadora (FOUCAULT, 2010).

Se no Núcleo de Saúde do presídio feminino minha permanência foi ao lado do jaleco branco, na cadeia de papel, faço sombra às Donagentes. Ali também o poder organiza as cores, mas a proximidade com o preto bagunçou meu binarismo tolo de antes da chegada. Nem só de preto repressor sobrevive uma menina, a vigilância é recheada de cuidados. No território das celas, não entram técnicos nem familiares, só as agentes de preto. Dra. Juíza é visitante de semestre, dra. Promotora ou dra. Defensora nunca as vi por ali. Pastoras oram aos domingos, mães chegam ao pátio aos sábados. De resto, a semana só é visitada por Donagentes e, a cada três dias, por mim, uma puxadora de plantão encantada com o recém-descoberto mundo da cadeia de papel.

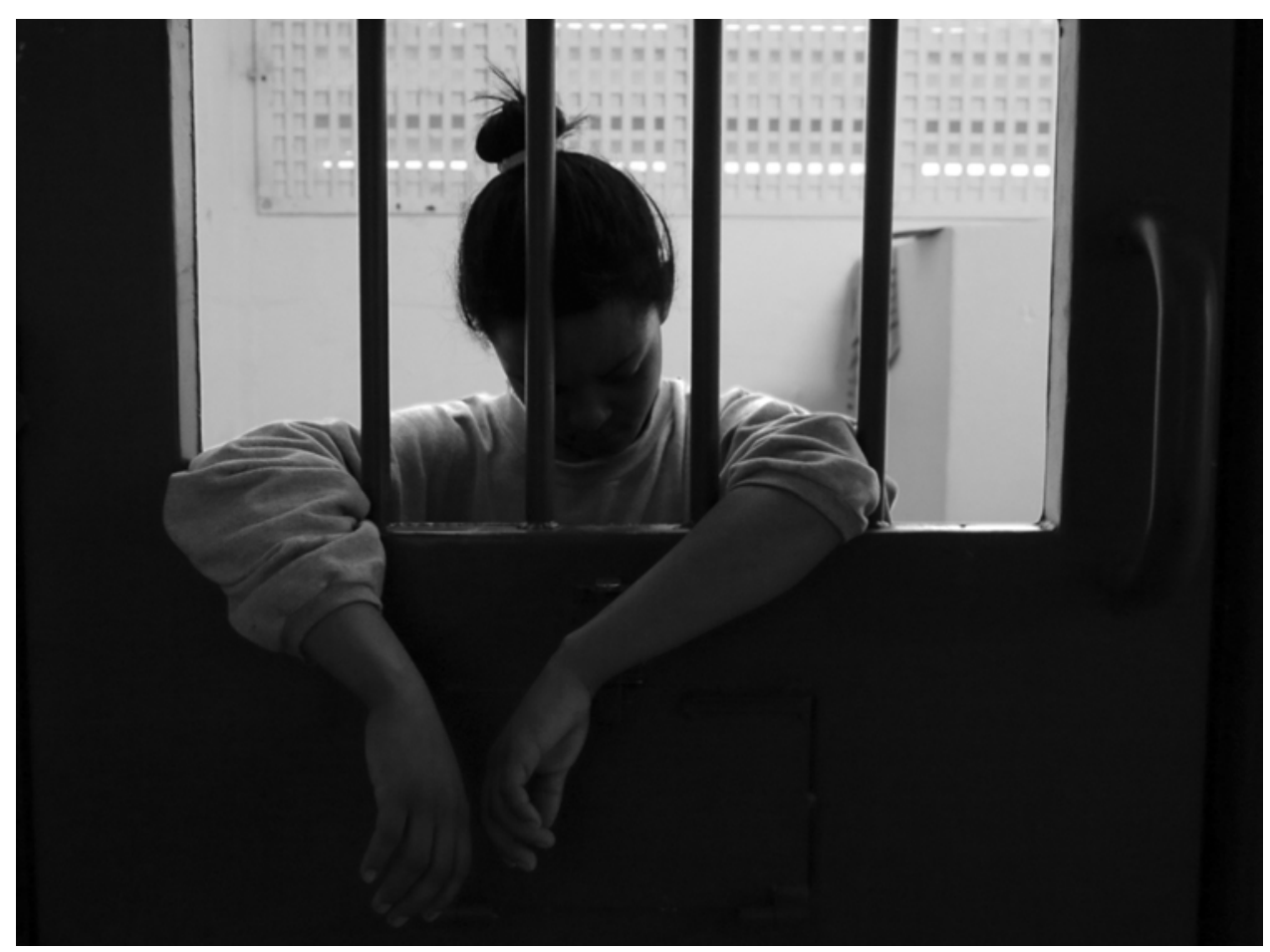

BARRACOS DE MENINAS. DEBORA DINIZ, 2015. 


\section{ESCRITAS E VIDÊNCIAS}

É da incerteza do presente que gostaria de encerrar este ensaio - não sei o que escreverei sobre os meses de puxadora de plantão na cadeia de papel. Por ora, prefiro pensar sobre os meios e jeitos com que escrevemos como pesquisadoras de cadeia. Há raiva e ressentimento pelo visto e vivido; a denúncia do escândalo de Zefinha exige pressa; o suicídio de Janete Maria no presídio reclama luto no fora. Somos autoras abusadas, e com razão; feministas cansadas do justo distante e militantes inquietas pelo equívoco do modelo punitivo. É verdade, o diagnóstico me parece correto; minha dúvida é sobre nossos modos para falar sobre isso tudo.

Há gênero nas pesquisas em cadeia, e mais do que um estilo literário: a corporificação da autoria agenda o campo. Gênero não é apenas a sexagem de nossos corpos e o dobramento com as formas de vivermos a sexualidade. É mais: gênero é um regime político de governo da vida pelo patriarcado (DINIZ, 2015c). Poderia ter contado minhas histórias de pesquisa pela sexagem das personagens - os loucos do manicômio, Zefinha, as presas ou as meninas bandidas. Essa é uma das formas de olhar gêneros nas pesquisas de cadeia. Eu ensaiei outra via: a da escritura e a da vidência. A escrita sobre crime, bandidagem e cadeia é masculina, está imersa no patriarcado e reproduz a linguagem hegemônica do gênero. A pesquisa e a escrita sobre cadeia são de homens e sobre homens.

Há duas formas de provocar minha tese da masculinidade do campo e suas formas de escritura e vidência. A primeira é covarde de tão simples. O campo do direito penal, da sociologia da punição e, mesmo, da criminologia é dominado por autores homens. As cadeias estão abarrotadas de homens presos. Crime, castigo e autoria são questões masculinas. Mas é a segunda versão da tese a que mais me interessa - a hegemonia dos homens impôs uma forma de falar sobre cadeia: a linguagem é a do sangue, da denúncia e do escândalo. Essas são estratégias impactantes, é verdade, mas receio pela potência de mobilização. Prefiro arriscar outros caminhos, quem sabe, o do encantamento - não falo poesia, não reclamo isso de linguagem poética sobre o horror da cadeia. Peço o encantamento de quem faz desaparecer o medo para dar lugar ao reconhecimento: escritura e vidência importam para tornar visível o escondido ou desaparecido.

\section{Modos de falar}

- Banho de sol: tempo de convívio fora da cela.

- Cadeia de papel: unidade socioeducativa de internação.

- Catatau: bilhete.

- Colete preto: carcereiro.

- Confere: procedimento da vigilância.

- Corre: trabalhos cotidianos.

- Donagente: agente de vigilância em unidade socioeducativa.

- Jaleco branco: profissional de saúde.

- Jega: cama de cadeia.

- Manicômio judiciário: hospitais de 
custódia e tratamento psiquiátrico.

- Massa: multidão de presas.
- Revista: procedimento da vigilância de checagem do corpo.

\section{NOTAS}

1 Uma versão deste ensaio foi discutida no I Seminário Internacional de Pesquisa em Prisão, promovido pela Fundação Getulio Vargas em São Paulo, em outubro de 2015.

2 Foucault se move por, pelo menos, quatro sentidos para acontecimento: novidade, regularidade, relações de força e método do trabalho histórico. Aqui me debruço na ideia do método da pesquisa histórica: escavação e novidade.

3 Depois da publicação do livro, fui proibida de retornar ao presídio. Mesmo com autorizações judiciais, a alegação da direção do presídio é escassez de escolta para me garantir a segurança.

\section{REFERÊNCIAS BIBLIOGRÁFICAS}

A CASA DOS MORTOS. Direção: Debora Diniz. Brasília: Imagens Livres, 2008. 1 DVD (23 min). AGAMBEN, Giorgio. Homo Sacer - o poder soberano e a vida nua I. Belo Horizonte: UFMG, 2007. ARTIERES, Philippe. Le livre des vies coupables: autobiographies de criminels. Paris: Albin Michel, 2014.

BUTLER, Judith. Relatar a si mesmo: crítica da violência ética. Tradução: Rogério Bettoni. Belo Horizonte: Autêntica, 2015.

DINIZ, Debora. A Casa dos Mortos: do poema ao filme. Revista TRAMA Interdisciplinar, v. 4, p. 21-35, 2013a.

. A custódia e o tratamento psiquiátrico no Brasil: censo 2011. Brasília: LetrasLivres e EdUnB, 2013b.

Cadeia: relatos sobre mulheres. Rio de

Janeiro: Civilização Brasileira, 2015a. Cadeia de papel: escrevo, por quê e para quem? Revista Liberdades, IBCCRIM, São Paulo, v. 19, p. 104-109, 2015b. Feminismo: modos de ver e mover-se. In: $O$ que é feminismo? Cadernos de Ciências
Sociais. Lisboa: Escolar, 2015c.

. The House of the Dead: the ethics and aesthetics of documentary. In: Macneill, Paul (Org.). Ethics and the Arts. The Netherlands: Springer, 2014. p. 79-87.

. Zefinha - o nome do abandono. Ciência \& Saúde Coletiva, v. 20, p. 2667-2674, 2015d. DINIZ, Debora; BRITO, Luciana. "Eu não sou presa do juízo, não" — Zefinha, a louca perigosa mais antiga do Brasil. História, Ciências, Saúde.

2016. No prelo.

DINIZ, Debora; PAIVA, Juliana. Mulheres e prisão no Distrito Federal: itinerário carcerário e precariedade da vida. Revista Brasileira de Ciências Criminais, v. 111, p. 313-328, 2014.

FARGE, Arlette. O sabor do arquivo. Tradução: Fátima Murad. São Paulo: EdUSP, 2009. FOUCAULT, Michel. A vida dos homens infames. In: . Estratégia, poder-saber: ditos e escritos IV. Organização e seleção de textos de Manoel Barros da Motta. Tradução de Vera Lucia Avellar Ribeiro. Rio de Janeiro: Forense Universitária, 2012. p. 203-222. 
Os anormais: curso no Collège de

France (1974-1975). São Paulo: Martins Fontes, 2010.

GOMÉZ, Antonio Castillo; Blas, Verónica Sierra (Ed.). Letras bajo sospecha: escritura y lectura en centros de internamiento. Gijón: Trea, 2005.
HARAWAY, Donna. Saberes localizados: a questão da ciência para o feminismo e o privilégio da perspectiva parcial. Cadernos Pagu, n. 5, p. 7-41, 1995.

LEVI, Primo. É isto um homem? Tradução de Luigi del Re. Rio de Janeiro: Rocco, 1988.

\title{
Debora Diniz
}

\author{
Brasília - DF - Brasil \\ d.dinizlanis.org.br
}

Doutora EM ANTROPOLOGIA. 